\section{Experiences of implementing hospital management information system (HMIS) at a tertiary care hospital, India}

management information

system

\author{
Lakshya Arora
}

Master of Hospital Administration, Tata Institute of Social Sciences, Mumbai, India, and

Feroz Ikbal

School of Health Systems Studies, Tata Institute of Social Sciences, Mumbai, India
Received 7 September 2020 Revised 18 November 2020 28 January 2021 Accepted 30 April 2021

\begin{abstract}
Purpose - Mumbai needs to be transformed into a world-class city as stated in the 2005-2025 development plan of Municipal Corporation. For this initiative, hospital management information system (HMIS) has to be implemented across $400+$ health facilities in the city.

Design/methodology/approach - A case study methodology was adopted to study HMIS implementation. Wave 1 of Phase 1 implementation of HMIS is carried out as a pilot project at Film City's Hospital, Mumbai, which "go-live" on 21st June 2018. The work for hardware and software implementation was awarded to HardSystems and Solutions Limited and SoftSolutions India Private Limited, respectively, through e-tender.

Findings - Provision of inadequate quantity of hardware, slowness of network or system, non-satisfactory training after observation confirmation and sign-off process, lack of data entry operators, mismatch in numbering systems in blood bank and many other challenges concerned with the specific departments had become a major impediment in the efforts to maximize number of patients registered into HMIS.

Practical implications - Even after providing many clinical and managerial benefits, being the first cloud-based centrally located HMIS in any of the hospitals in the city, it imposes a major challenge for the management in terms of resistance of employees toward technology and need for the adoption of theoretical models for implementing change for the overall organizational development.

Originality/value - To the best of the authors' knowledge, no other teaching case study is conducted to study the HMIS implementation in large-scale public health-care services. This is a dummy case study for teaching exercises. The identity of the stakeholders, organizations and events has been masked to maintain confidentiality.
\end{abstract}

Keywords Change management, Organizational development, Health-care services management, Hospital management information systems, Pilot project

Paper type Case study

(C) Lakshya Arora and Feroz Ikbal. Published in Vilakshan - XIMB Journal of Management. Published by Emerald Publishing Limited. This article is published under the Creative Commons Attribution (CC BY 4.0) licence. Anyone may reproduce, distribute, translate and create derivative works of this article (for both commercial and non-commercial purposes), subject to full attribution to the original publication and authors. The full terms of this licence maybe seen at http:// creativecommons.org/licences/by/4.0/legalcode

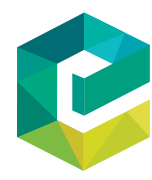

$$
\begin{array}{r}
\text { Vilakshan - XIMB Journal of } \\
\text { Management } \\
\text { Vol. 20 No. 1, 2023 } \\
\text { pp. 59-81 } \\
\text { Emerald Publishing Limited } \\
0973-1954 \\
\text { DOI 10.1108/XJM-09-2020-0111 }
\end{array}
$$


$\mathrm{XJM}$

20,1

\section{Background}

It was a dewy evening of Mumbai in July 2018 and a biscuit falls into the hot coffee which Medical Superintendent of Film City's Hospital, Mumbai was dunking into his huge vintage cup.

Deputy Medical Superintendent and hospital management information system (HMIS) Nodal Officer at Film City's Hospital bought a letter sent by one of the Heads of a Clinical Department to his office. It was mentioned in the letter that in most domains of the HMIS, the providers have not completed the modules and required integration which they have requested them to make as per the departments' clinical and documentation requirements. The letter added that the training team was helping them only with cursory skills which they could learn by themselves once the modules would be effectively designed and given. Hence, the representatives of SoftSolutions India Private Limited were suggested to be called in a meeting along with Heads of all the Departments and other users of the system in the presence of Medical Superintendent and Director to avoid financial losses to the healthcare system.

The Deputy Medical Superintendent and the HMIS Nodal Officer discussed with the Medical Superintendent that it was only one among many letters received by HOD of many departments of the hospital where HMIS was implemented as a pilot project by the Director in the past few months.

Informatics involves information acquisition, organization, validation, storage, retrieval, integration, analysis, communication and presentation, using IT as a key resource (Lifshitz et al., 2007; Sinard, 2006). HMIS is defined as the "computer system designed to ease the management of all the hospital's medical and administrative information and to improve the quality of healthcare" (Degoulet and Fieschi, 1997). An EHR system comprises "the longitudinal collection of electronic health information for and about persons, where health information is defined as information pertaining to the health of an individual or health care provided to an individual. Critical building blocks of an EHR system are the electronic health records (EHR) maintained by provider. . and by individuals" (National Institutes of Health, 2003).

At present, most of the Indian hospitals are adopting HMIS as a way of automation and digitalization of their health-care records.

\section{Film City's Hospital, Mumbai}

Bombay, the very first possession of Britishers in India, came to King Charles II of England in 1661, when he married the Portuguese queen, as part of the royal dowry. Through Corporation Resolution No. 512 which was dated August 12, 1996 under Maharashtra Act, XXV, 1996, the name "Bombay" has been changed as "Mumbai."

Greater Mumbai is presently a metropolitan aggregation of around 18 million residents (world's six largest and largest in India). The port city accounts for most of foreign trade in India as well as government revenues, being one of the major hubs for education, research, development and technology in India (MCGM, 2019).

The Film City's Hospital situated in the heart of Mumbai is a 1,000-bedded tertiary care facility with around 30 clinical departments where every year more than 55,400 patients are admitted and more than 280,000 patients (new and old) are treated in out-patient department. More than 21,000 operations (major and minor) are performed and 4,200 deliveries are done every year.

In addition to the routine medical services, it also offers various super-specialty services in nephrology, neurosurgery, endocrinology, gastroenterology, cardiology and cardiac vascular and thoracic surgery. This hospital has well-equipped intensive care units for 
medical, surgical, cardiac and neonate patients. The hospital has its own blood bank and component therapy unit, which provides services round the clock. A whole body CT scanner, cardiac catheterization system and spect camera, etc. are also installed at the hospital. It also has independent hyperbaric oxygen therapy chambers.

The hospital levies fees from the patients at subsidies rate and efforts are made to provide the best and excellent patient care (MCGM Health Department, 2019).

Why hospital management information system. ..?

India's 12th 5-year plan highlights the need to improve HMIS throughout the nation and a possible investment in health IT in the public health system (Twelfth Five year Plan Draft 2012, 2017). Multiple findings have reported the advantages of HMIS implementation (Hillestad R et al., 2005; Wang et al., 2003; Frisse and Holmes, 2007; Shekelle et al., 2006).

HMIS is considered to be the most promising instrument to improve the overall efficiency, safety and efficacy of the health service (Basit et al., 2006). Wide and effective use of HMIS improves the quality of health care (Frere, 1987); minimize adverse events; reduce the cost of medical care (Lun, 1995); increase administrative productivity improvements (Kuruvilla et al., 2004); reduce documentation as well as enhance access to affordable treatment (Basit et al., 2006; Yasnoff et al., 2000).

Municipal Corporation aspires Mumbai to be transformed into a millennium and worldclass city as stated in the development plan 2005-2025. For this to happen, Mumbai requires to be distinguished about the quality of life aspect by improving the quality of citizen welfare services. As part of this initiative, the HMIS has to be implemented across $400+$ health facilities across the city.

There is the availability of digital access original data through HMIS which can be used as a strong tool in the decision support system for the Film City's Hospital management. The HMIS data can be used for analysis as well as for forecasting purposes. The electronic medical records (EMRs) as well as picture archiving and communication system (PACS) generated can be of great use for the clinical purposes for better diagnosis and treatment. The HMIS data can also be used for drug calculations and better scientific inventory management practices at the hospital.

\section{Hospital management information system implementation at Film City's Hospital}

Literature have shown that implementation and improvement in HMIS to guide policy and management decisions has found essential space in countries such as Peru, Tanzania, Solomon Islands, Caribbean, Lesotho, Honduras, India (Uttar Pradesh) and Kryragya Republic (World Bank Reports, 1993, 1999, 2000, 2001; Commission on Health Research for Development, 1990).

The work of software implementation and post-implementation of HMIS in the film city covering 4 major hospitals, 1 dental hospital, 18 peripheral hospitals, 5 specialty hospitals, 28 maternity homes, 161 dispensaries and 183 health posts was awarded to SoftSolutions India Private Limited.

As per the directives, Wave 1 of Phase 1 implementation of HMIS is carried out at Film City's Hospital as a pilot project. Wave 2 of Phase 1 was planned to be implemented at other three major hospitals in the city and thereafter at balance health-care locations (Mukul, 2018).

It was decided to form a committee to commence the viability and feasibility of Wi-Fi services project at Film City's Hospital and the standing committee sanction was received for awarding the work for hardware and network implementation at the Phase I Hospitals 
and the LOI of worth Rs. 50+ crores for the prestigious project is issued to HardSystems and Solutions Limited. Further, a pilot implementation is planned to be carried out at few departments in Film City's Hospital which "go-live" on 21st June 2018 (MCGM IT Department, 2019).

\section{Bid document for hospital management information system}

The HMIS software pilot project at Film City's Hospital was awarded to SoftSolutions Private Limited through evaluation of technical and commercial bids by e-tender process, initiated in July 2016. SoftSolutions, also as part of their scope, conducted a site survey for hardware infrastructure for all health-care institutions in the city. The exact quantity and minimum specifications for various hardware and infrastructure have been provided by SoftSolutions post site survey.

The purpose of this bid document is to select an agency for not only the supply but also the hardware and network components' installation, testing, commissioning and maintenance for the health institutions.

A Bid Evaluation Committee (BEC) was appointed to examine and assess the submitted technical as well as commercial bids. The BEC reviewed the bids to decide if they're really complete, able to respond and if the bid format complies with the bid specifications. In a bid that does not represent a material variance, it was waived for any informality or nonconformity and the bidder with the lowest cost submitted (L1 rate) in the commercial bid opening was awarded the contract.

As per this bid document (MCGM Bid Document, 2018), pre-implementation scope till golive in the health-care institutions was as follows:

- Submission of inception report.

- Supply, installation and commission of various hardware and network components along with required accessories at health institution.

- Undertake required passive structured cabling (including patch chord, faceplate with input/output connector, laying of LAN and fiber cable (if required) with proper labeling, testing certificate and others).

- The device should be tested before mass-installation (operating system compatibility, software, drivers, etc.).

- The supplier should take care of all installation and support issues that are faced by the end-user, for all hardware and software supplied as part of the purchase order. This would include installation and support for security functions, user configuration, LAN configuration, etc.

- Addition of a desktop PC to the security device is to be done by the implementation agency.

Post-implementation scope for the operation and maintenance period was:

(1) In-warranty annual technical support for hardware and network components services for a period of five years.

(2) The following are additional points for the scope of the implementation agency:

(3) The Wi-Fi/network device shall be connected to the local area network.

(4) The supplier shall disable unnecessary services, protocols and ports.

(5) When installing software, ensure that only required software is installed and the latest versions of all software including all recommended security patches are updated. 
(6) Disable or remove redundant software/services (including program, machine utilities and network services).

\section{Pre-requisites for hospital management information system pilot project}

- The Assistant Medical Officer (AMO) of the hospital was appointed as the HMIS implementation nodal person from Film City's Hospital for coordinating with the internet service provider and hardware supplier appointed by HardSystems and Solutions Limited, implementation of software by SoftSolutions and coordinating with various departments for providing solutions to any challenges faced.

- Site readiness - the representative of SoftSolutions visited each department of the hospital for finalizing the network points, in consultation with the Head of Departments (HODs).

- For the implementation of HMIS, one server room and one room for hardware and software support staff for the hospital and UPS room per building were identified and subsequently handed over to HardSystems and Solutions Limited, as per the specification (The Hindu, 2018).

- The support staff room was used by HardSystems and Solutions Limited for storing the equipment during the installation.

- The civil work, if any, required for the network installation, server room and UPS room readiness was carried out by the Hospital Assistant Engineer (AE), Civil Department.

- The furniture, if any, required for the HMIS hardware was identified and procurement was carried out by the Hospital M\&E department.

- The electrical work for HMIS implementation was carried out through the Chief Engineer (M\&E) department. The concerned M\&E engineer from the hospital coordinated with the representative of SoftSolutions and HardSystems and Solutions Limited.

The Phase 1 pilot project implementation at Film City's Hospital was done at four clinical departments, including gastroenterology, psychiatry, nephrology and oncology services and various supportive departments including Assistant Medical Officer (AMO) office, Blood Bank, Registration Counter, Kitchen and Dietary Services Department, Linen and Laundry Department, Pharmacy Department and Medical Social Work (MSW) Department. The Phase 2 implementation was done in remaining supportive services and six other clinical departments, including General Medicine, General Surgery, Orthopedics, Neurology, Cardiology and Gynecology and Obstetrics. Presently, a total of 32 HMIS modules have been implemented at Film City's Hospital.

\section{Hardware and software implementation}

As the number of patients was increasing in the waiting areas of the clinical departments, Deputy Medical Superintendent took a round with HMIS nodal officer to locate any patientfree area or store rooms in IPD building.

After the functional requirement study and the hardware survey did from June to September, 2016, the Digital Laboratory and Security room on ground floor of IPD building of the Film City's Hospital was allotted for hardware storage. A $24 \times 7$ helpdesk was also created to give instant solutions to the arising issues in the software or hardware. 
$\mathrm{XJM}$

20,1

As per directives, 200 customized portable computer trolleys (to be used for computer-onwheels) were provided as per the requirements and storage area in the departments.

Under Software Research Survey (SRS) up to September 2016, software customization for medical specialties was done after studying the workflow of major hospitals of Mumbai, for surgical specialties, radiology and central sterile services. Sub-committees were formed in each of these hospitals to monitor the process of customization of software, and sessions to sensitize nursing staff, technicians, pharmacists, registration attendants, etc. were conducted across all the hospitals. Weekly or sometimes fortnightly review meetings were held at the Film City's Hospital. Also, various teams visited multiple public, private and trust hospitals across the city to study already existing HMIS implemented in these hospitals (MCGM IT Department, 2019).

\section{User acceptance tests and finalization of hospital management information system modules}

Documented literature suggests that the degree of end-user satisfaction is a pivotal factor of an information system's success (Bailey and Pearson, 1983). Many other studies have stressed the significance of levels of end-user satisfaction (Doll and Torkzadeh, 1988; DeLone and McLean, 1992).

During the user acceptance test-1 (UAT-1), there were 517 observations noted in module testing which was carried out up to March 21, 2017, by the doctors and other representatives.

Thereafter, in April 2017, a UAT observation confirmation process (also known as system requirement specification reconfirmation) was carried out by SoftSolutions with representatives from various health-care facilities who were assigned for each module so as to prepare SRS 1.1 with more precise information and requirement to aid the development of HMIS.

With reference to the OPD module, about 318 proformas from 29 departments were handed over to SoftSolutions on 9th June 2017 for developing the EMR for the OPD module. Considering each proforma was unique and also an easy-to-use system is to be developed, SoftSolutions has developed a solution and the same was shown to a team of doctors of each department concerned with the OPD module to check the functionality and provide their inputs for the same, so that the precise requirement can be incorporated in the SRS 1.1.

Further, SoftSolutions have documented the information provided during and after the UAT 1 and UAT/SRS reconfirmation in the latest SRS version 1.1 and the same was ascertained by the team of representatives who had provided the information during the UAT/SRS reconfirmation and corrected the same if necessary and provided the sign-off for the respective module SRS 1.1. On completion of the activity, UAT-2 (inter-module) and thereafter UAT-3 (integrated) were planned to be conducted.

On the basis of all the three UAT and UAT observation confirmation processes conducted for different modules, there were a number of change requests made by concerned HODs/departments which after approval from nodal officers were incorporated through some policy decisions for requirements which were taken by the administration.

It was finalized by the management that the short message service (SMS) would be used for registration and inpatient referral only. It is not necessary to send SMS for every activity. For easy workflow of IT services, digital signatures were assigned for important decisions, for legal, medico-legal cases, birth and death certificates. 


\section{Recruitment of data entry operators and training of hospital staffs}

Deployment of data entry operators (DEOs) for assisting the hospital staff related to the implementation of HMIS was done through prescribed norms of recruitment for different departments for three working shifts.

The training was well planned by a team of SoftSolutions and all the requirements including space and other resources were allocated. Training was done in two parts, which involved orientation lectures and hands-on session conducted in the first and second weeks of February 2018, respectively.

It was decided to use India's first indigenous Web-based PACS Medsynapse for training doctors and staff of radiology department. It is developed on advanced technologies and provided a full range of features and tools for image processing, distribution and archival. It is very user-friendly, scalable and affordable PACS with more than 20,000 installations in 40 countries.

A training completion certificate on specific HMIS module was awarded to each employee after successful completion of training.

For the purpose of logging into HMIS computers and application, employee's ID-based default login and password systems were generated, which were later allowed to reset by the users. Thus, all the resident doctors and other staff got access to the HMIS system.

An HMIS refreshment training with proper consultation with Team SoftSolutions was provided once again in October 2018 after proper implementation of all the 32 modules in the system.

\section{Dry run and go-live}

A dry run was conducted in the selected clinical and supportive services departments of Film City's Hospital in Phase 1 from April to June 2018. After the required improvements needed the pilot project "go-live" for Phase 1 of Wave 1 from 21st June 2018 (MCGM RTI, 2019).

\section{Overcoming hospital management information system challenges}

Provision of an inadequate quantity of hardware either because of lack of storage space or because of unavailability of furniture and computer trolleys had become a major impediment in the efforts to maximize the number of patients registered into HMIS at Film City's Hospital, e.g. super-specialties such as nephrology and gastroenterology have an average outpatient load of around 100-150 patients per OPD. But only three computers have been provided for doctors and one for the nursing staff in the OPD of super-specialties.

Because of the slowness of the network or the system, particularly after 11:00 a.m., patients are inconvenienced as they have to wait for long periods till the EMRs are filled and prescriptions and laboratory/radiology requisitions are generated. At times, patients are reluctant to wait for the procedure to be completed. Consequently, only a few requisitions of laboratory and radiology investigations had been processed through the system. It was decided to put more LAN cables but when the issues persist, new Wi-Fi dongles were thought to be procured for every department in the future (DNA, 2019).

Also, a major challenge is that integration of HMIS with various government and insurance schemes is to be undertaken and also a separate budget is to be allocated for HMIS consumables.

HMIS Nodal Officer conducted an immediate evaluation and the following challenges were reported to be faced by some important clinical and supportive services departments. 
$\mathrm{XJM}$

20,1

Department of gastroenterology

One of the issues of the gastroenterology was that all the hospitals in the film city were using different systems for capturing endoscopy reports. Also other investigations such as manometry, PH, fibroscan and breath hydrogen were intended to be managed well so that different reports and PDF can be uploaded in HMIS. The report's structure given in HMIS was discussed with concerned IT team to check for the network link to the system.

\section{Department of psychiatry}

As soon as the recreational activities started for the admitted patients, the HOD of Psychiatry Department entered the IPD area. HMIS Nodal Officer was waiting for him to ask for required modifications.

He said, "Wires need to be covered to protect against damage by the psychiatric patients. Sub-departments like Psychology, Social worker and EEG are also to be included in the system." HMIS Nodal Officer carefully noted the desired changes. When inquired about the psychiatric OPD, implementation of electronic queue management system monitor was suggested.

\section{Pediatrics department}

On meeting with the Professor of Pediatrics while he was checking the nutritional chart for a three-year-old child, the Nodal Officer asks her to raise the concerns regarding HMIS implementation. She swiftly enumerated that the weight, age and height data have to be integrated for making relevant WHO charts and growth curves for classifying patients with severe acute malnutrition or moderate acute malnutrition. She added, immunization record is also to be included in IPD paper. If a vaccine is missing as per national immunization program, a warning has to come on the system. Automatic calculation of surface area is required for prescribing certain drugs. Integration with certain government schemes is also required.

Opening her smart tablet, the HMIS Nodal Officer checked the relevant schemes available in the Film City's Hospital and asked, "Should Janani Suraksha Scheme also be integrated?" for which she got the affirmative response.

Professor of Pediatrics explained to the Nodal Officer that daily reporting/monthly data have to be available disaggregated in terms of age, gender, notifiable diseases and monsoonrelated illness. In addition, the multiple diagnoses have to get sited separately because they are not mutually exclusive. Also, referral list has to be made comprehensive to include physiotherapy, occupational therapy, dietetics and speech therapy in addition to clinical/lab departments.

\section{Radiology department}

With the use of Digital Imaging and Communications in Medicine standard and Health Level 7 communication protocol, vendors communicate with the radiology imaging management system termed PACS. Undoubtedly, a major concern in radiology department is to combine the images of each analysis with other important patient records and enhance interoperability with radiology information system and HMIS (Cummings, 1995; Offenmuller, 1997).

According to recommendations of PACS Support Engineer given to HMIS Nodal Officer of Film City's Hospital, "open office" does not support PACS reporting. In addition, the automatic transfer of stored images from USG machine to HMIS was not taking place. Therefore, the HOD of Radiology requested that the licensed access to 3D-MPR viewing be provided to all the radiology employees, including CT/MRI technicians. Furthermore, with 
the view of additional $\mathrm{CT}$ and MRI machines being instilled with additional workload in the near future, approximately 70 licensed accesses needed to be made available to increase the ease, efficiency and speed of reporting. The licensed MS office is also preferred to maintain the integrity and uniformity of the departmental work.

Also, while reporting the patient on PACS, considerable time was consumed in logging in as well as in opening a particular patient. It was difficult to interpret whether the slowness could be attributed to the slow speed of the network or slowness of the operating software.

In addition to this, there was the need for early integration of revenue counter and the central laboratory with the HMIS system for the better functioning.

\section{Laboratory and diagnostics services}

Diagnostics is a data-intensive specialty, and laboratory data is often used in addition to patient services to record continuous improvement, performance management, outcome analyses and research studies (Cowan, 2005; Young, 2000). At the center of most laboratory activities is the laboratory information system. Workflow management, specimen monitoring, data entry and reporting, regulatory enforcement assistance, code acquisition, interfacing with several other applications, archiving, inventory management and provision of billing information are its features (Eleveitch and Spackman, 2001; Pearson et al., 2006).

After the complete day consultation with various departments, when HMIS Nodal Officer reached the laboratory services at the end of the day, the following recommendations were provided:

- For appointment generation counter: token generation facility for the same-day blood collection of patients has to be incorporated in the system. For the token generation, a fast printer device was required as a large number of patients need to be handed over in a short period of time.

- For labeling counter

- Quality of bar code labels need to be improved. Printouts sometimes are not readable and may face problem in scanning. The problem was discussed with the Project Director, HMIS.

- Consumables such as printer roll, appropriate sized labels are not easily available in the hospital.

- For collection table: It was discussed with the IT in charge, SoftSolutions, that wallmounted all-in-one PC units with bar code scanner facility or tablets with in-built scanner need to be installed in OPD for scanning the collected blood samples.

- Blood sample processing: Appropriate diagnostic equipment such as blood cell counter and automated biochemistry analyzer have to be procured, which can be integrated with HMIS.

\section{Blood bank services}

The blood bank system consists of an autonomous blood center responsible for human blood procurement, storage and distribution (Li et al., 2007). Because blood bank services are vital segment of the Film City's Hospital and there were major concerns raised by the employees in the department, Medical Superintendent called for an urgent board meeting (Tables 1).

A unique number was given to each blood bag in the blood bank. This number is followed through the life of that blood bag, i.e. the same number applies at blood group, 
serological tests, stock taking, cross-matching and issue of blood bag to patients. As on 30th July 2018, the blood bank numbers were at "Indoor 905," "Outdoor 9888" and "Brought from i.e. BF 1186."

The HMIS data entries in Blood Bank were attempted since 26th July 2018; however, the HMIS software is unable to match the actual bag numbers because it begins by default 001 , 002, 003, etc. Because of this error, the outdoor bag number 8434 may be entered in HMIS as bag number 0004, indoor bag number 894 entered in HMIS as bag number 0005 and so on.

This numbering system, if continued, could have created utter chaos at all levels. Online bloodstock will show wrong bag numbers available to technicians for a cross-match. Issued bags will not correspond to the actual blood bag issued, thus resulting in confusion at a blood bank and clinician level.

In addition, serious mistakes in identifying and discarding of seropositive bags (HIV, Hepatitis B, etc.) can occur because of an incorrect numbering system.

Given the sensitive nature of blood bank work, the slightest error in numbering can cause disastrous results for the patient's life. Any kind of dual numbering system, as suggested by the HMIS technical team, will further compound the problem, double the workload and invite severe adverse remarks from the FDA.

Because Film City's Hospital is stationed for the pilot study, any errors can get carried forward and adversely affect the working of other hospitals and other blood banks too. In view of this serious medico-legal and ethical implications, it is essential that HMIS number entries have to categorically match with available numbering for blood bags.

\section{Pharmacy prescriptions and dispensary services}

In outpatient health care, the drug management process is a multifaceted relationship between patients, prescribers and pharmacists, which is also enabled by HMIS (Tamblyn, 2004). Electronic medication management has the ability to allow a secure process, but errors may also be created (Bates et al., 2001).

At Film City's Hospital, after consultation with head pharmacist, HMIS Nodal Officer noted that a standard prescription format should include name of the drug, preparation, strength, dose, route of administration, frequency and number of days. The route of drug administration should be comprehensive and must also include intradermal, intra-thecal and intra-ocular routes.

It was recommended that the prescriptions need to be in terms of both generic and brand names. Allergies must be a mandatory field, which needs to be pop out during prescriptions. Starting and end dates should be integrated especially for drugs with progressive decreasing doses. At once, no medicines should be prescribed for more than one month.

It was suggested to improvise the SAP system, based on the positive features of government's "e-Aushadi program" which includes:

- Need for surplus and shortage alerts.

- Rigorous quality control of medicines should be mandatory and built-in using impaneled NABL-accredited laboratory.

\section{Achieving the milestones}

The HMIS is being implemented to improve the quality and responsiveness of health-care services in health-care network in the film city (Tables 2 and 3). 


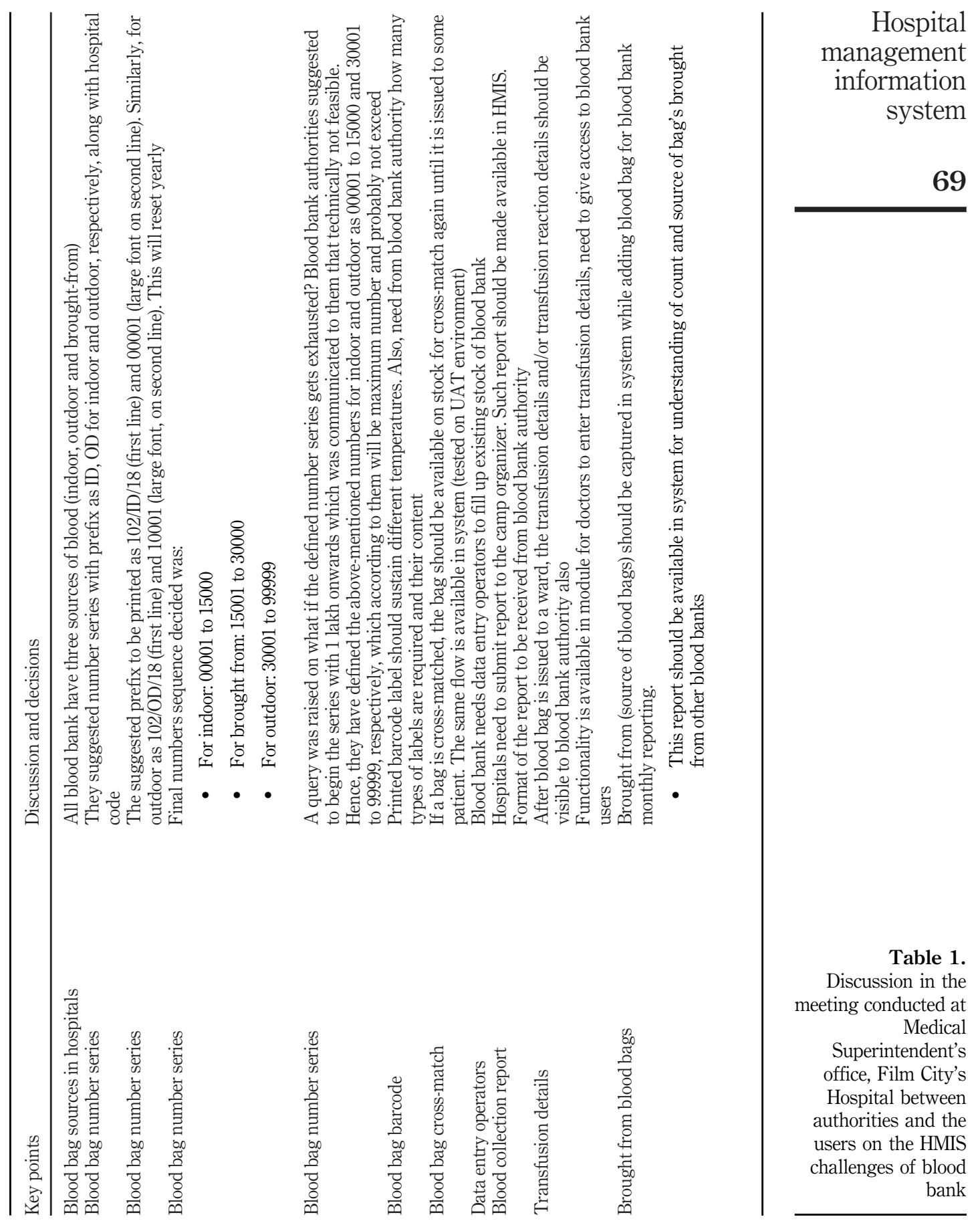


$\mathrm{XJM}$

20,1

70

\section{Features of hospital management information system implementation at Film}

City's Hospital

The unique features of the HMIS system at Film City's Hospital are that this system is first of its kind in any of the city's hospitals that uses a cloud-based centrally located system in which as much as 32 clinical and supportive services HMIS modules are covered. It is made possible to achieve inter-departmental and intra-departmental connectivity in Film City's Hospital through this system. In addition, this cloud-based system also allows central access to data through any city's health-care systems, thus enhancing inter-hospitals connectivity (MCGM RTI, 2019).

\section{Hospital management information system implementation - the road ahead}

There is a lack of DEOs in some departments. To enhance the time and cost-effectiveness and to achieve digitization through increasing reach to more number of patients, it was decided to implement "Speech to Text" software in the OPDs based on the principle of "machine learning." The SoftSolutions team has already started taking voice samples of the doctors in the OPDs, and to test the effectiveness of the software, the trial run has been started in the Psychiatry and General Medicine OPD of Film City's Hospital.

Also, at the registration department, issue of digitalized health card to every patient with Unique Hospital Identification Number and bar coding on it has been started. In the future, the bar scanners will be incorporated to save time at various points in the hospital.

Most of the users are still very resistant in the use of technology in the hospital as they are adapted to traditional manual data entry and calculation methods. The percentage of EMR completion still has to be improved.

Deputy Medical Superintendent along with the HMIS Nodal Officer discussed with the Medical Superintendent, Film City's Hospital that there is a need for adoption of "John Kotter's Eight-Step Plan" for implementing change for user acceptability for the overall organizational development and to reinforce the future dream which she had seen of digitalized health-care systems in digitalized India.

\section{Discussion}

Several studies on implementation of HMIS in developed countries (Ash et al., 2003; Ball, 2003; Berg, 2001; Benson, 2002; Little Johns et al., 2003, Joel Rodrigues, 2009; Lippeveld et al.,

Table 2.

Progress of HMIS implementation at Film City's Hospital up to February 2019

\begin{tabular}{lcc}
\hline Element & Target & Achieved \\
\hline Total desktops installed & 968 & 624 \\
Total installed laptops & 25 & 18 \\
Total printers installed & 821 & 719 \\
Total trolley distributed & 200 & 200 \\
Total modules working & 32 & 32 \\
Number of data entry operators recruited & 80 & 62 \\
\hline
\end{tabular}

\section{Table 3.}

Digitization through electronic medical records (EMRs) at Film City's Hospital

\begin{tabular}{lccc}
\hline EMR usage report & December 2018 & January 2019 & February 2019 \\
\hline Total patient registration & 16,755 & 26,727 & 21,245 \\
Total EMR completed & 2,958 & 9,628 & 8,352 \\
Percentage EMR completed & $17.65 \%$ & $36.02 \%$ & $39.31 \%$ \\
\hline
\end{tabular}


1992; Dudeck et al., 1997) had reported various challenges, including those in managing infrastructure, integration, inter-departmental issues, technical requirements, data and software issues, end-user contribution, standardization of terminologies, training needs and ignorance of hospital administration. In developing nations, numerous health-care professionals associate information systems with filling of infinite registers, collecting information and submitting reports without sufficient input, making HMIS "data-driven" instead of "action-driven" (Sandiford et al., 1992; Smith et al., 1988). Similarly, in this case study, although being an Indian hospital, managing infrastructure in terms of space for computers, trolleys and other accessories became a major challenge. Allocating areas for installing LAN and rooms for information technologist in a crowded hospital was not that easy task. In this case study, the hospital also faced inter-departmental and inter-hospitals issues with respect to integration and standardization of clinical domains and report structures, respectively. Even after adopting the HMIS principles in several trainings, many employees, especially elder age, felt the need for technical assistance. In addition, the poor doctor-patient ratio and the downtime of the server made the work more complicated as in some of the departments, employees started doing dual entries (both in register and computer) to prevent loss of any data.

Several issues have been identified in the review of reports and studies in low-income countries (Gladwin, 1999), such as general organizational and management difficulties (Campbell et al., 1996; Braa et al., 1997; Azubuike and Ehiri, 1999); data acquisition and processing concerns (Robey and Lee, 1990; Jayasuiriya, 1999; Lippeveld et al., 2000); inadequate use of information (WHO, 1994b, 1999; Braa et al., 1997); over-reliance on epidemiological data or specific surveys (Husein et al., 1993; Sapirie and Orzeszyna, 1995); and paucity of an integrated information strategy for the organization (Van Der Lei et al., 1993). In a similar way, in this case study also, many departments in the hospitals faced challenges around complexity, inconsistency and poor integrity of the system. Although the management tried to ensure the effectiveness, incidents such as mismatch in blood bag numbering in HMIS posed a major ethical issue. There were multiple concerns around data acquisition at revenue and cost centers of the hospital. Although management took corrective and preventive actions, it was reflective of a strategy which would have been well integrated prior with clinical understanding and principles of change management.

Several studies have been conducted on interface design methodologies (Shearer et al., 1997; Arreola et al., 1997), and among the unidirectional, bidirectional and integrated workstations (Levine, 1990), the interface with more consistent information base is most preferred (Veader, 1997). Studies have reported that an integrated radiology network enhances the efficacy of physicians, minimizes costs, decreases the amount of repetitive or unnecessary tests and increases the quality of care (Gibby and Mciff, 1997). In addition, owing to the extensive adoption of electronic radiology reporting systems, filmless radiology systems and speech recognition, there have also been considerable radiology workflow efficiency improvements (Mariani et al., 2006; Gay et al., 2002; White, 2005; Ralston et al., 2004). Similarly, in this case study, it was observed that with administrative efforts and understanding employee training needs, the number of repetitive tests was reduced. There was a direct benefit in lowering turnaround time and publishing more reports. The better integration and consistency of the PACS will help in increasing the profit per unit volume for the radiology department.

HMIS is important in its ability to resolve issues such as increasing laboratory volume with outreach programs; intensified EMRs integration; and the subsequent need to combine fragmented information systems, laboratory resource shortages, patient safety, cost control, central control of subspecialties, rising demand for laboratory diagnostics and customized 
intervention (Becich et al., 2004; Sinard and Morrow, 2001). In this case study also, HMISintegrated EMR played a significant role in decreasing the average waiting time for the patients for receiving the laboratory reports.

Child clinicians frequently feel that there is little utility of health information systems in pediatrics because they tend to be structured for adult services (Johnson, 2001). There are several functional areas, such as immunization records (Smith, 1988), growth monitoring (Rosenbloom et al., 2006), drug dosing (American Academy of Pediatrics, 2004), patient recognition (Kuther, 2003) and decision support systems (Miller et al., 2001), which are so vital to the treatment of children and adolescents that their omission contributes to the system hindering quality pediatric care. In this case study, with the discussion with HMIS Nodal Officer, the pediatric department was able to design a customized module which had unique characteristics as compared to any adult-based systems. Drug dosage and calculations, immunizations and growth-monitoring systems were integrated successfully.

Literatures have shown that implementation of computerized blood bank inventory and emergency services (Catassi and Petersen, 1967) and blood bag system (Ali et al., 2017) plays a significant part in hospital's decision-making systems (Li et al., 2008). Similar results were observed in this case study also.

Mohapatra (2009) notes that combining in-patient, pathological and inventory management of hospital pharmaceutical stores enables to enhance the quality of service and efficiency while reducing operating costs. This economic benefits can be reflected in the price, which gives customers more good value. The use of HMIS has been proposed as a way to minimize prescription errors by increasing the readability, standardization and availability of information or providing automatic controls for possible drug-related issues, but the findings are inconsistent (Huckvale et al., 2010; McKibbon et al., 2011, 2012). In this case study, the findings suggested that the use of HMIS was helpful in inventory management once the employee got well trained in inventory modules and it generated profitability for the hospital.

Literature shows that during the process of automation, important performance variables involved in the phase of change management are organizational structure, technology infrastructure and implementation approach (Galliers and Sutherland, 1991; Lubitz and Wickramasinghe, 2006; Nolan, Norton and CO, 1992). Emergent philosophy is more complex (Markus and Robey, 1988) than imperative perspectives (Robey and Boudreau, 1999), stressing a reciprocal instead of a one-way relationship involving technology and organization. Findings of this case study suggest that the management should have strategically thought about the change management perspectives in a visionary sense before taking the step for HMIS implementation. Most of the elder employees were resistant to change and found the system more complex. In terms of ease of use of HMIS, more than half of the employees were either neutral or disagreed in their responses.

\section{References}

Ali, R.S., Hafez, T.F., Ali, A.B. and Abd-Alsabour, N. (2017), "Blood bag: a web application to manage all blood donation and transfusion processes", Paper presented at the 2017 International Conference on Wireless Communications, Signal Processing and Networking (WiSPNET).

American Academy of Pediatrics (2004), "Committee on fetus and newborn. Age terminology during the perinatal period. Pediatrics", Vol. 114, pp. 1362-1364.

Arreola, M., Neiman, H.L., Sugarman, A., et al. (1997), "Implementation of a radiology electronic imaging network: the community teaching hospital experience", Journal of Digital Imaging, Vol. 10 No. S1, pp. 146-149. 
Ash, J.S., Gorman, P.N., Lavelle, M., et al., (2003), “A Cross-Site qualitative study of physician order entry", Journal of American Medical Informatics Association,

Azubuike, M.C. and Ehiri, J.E. (1999), "Health information systems in developing countries: benefits, problems and prospects", Journal of the Royal Society for the Promotion of Health, Vol. 119 No. 3, pp. 180-184.

Bailey, J.E. and Pearson, S.W. (1983), "Development of a tool for measuring and analyzing computer user satisfaction", Management Science, Vol. 29 No. 5, pp. 530-545.

Ball, M.J. (2003), "Hospital information systems: Perspectives on problems and prospects", International Journal of Medical Informatics, Vol. 69 Nos 2/3.

Bates, D.W., Cohen, M., Leape, L.L., Overhage, J.M., Shabot, M.M. and Sheridan, T. (2001), "White paper - reducing the frequency of errors in medicine using information technology", Journal of the American Medical Informatics Association, Vol. 8 No. 4, pp. 299-308.

Benson, T. (2002), "Why general practitioners use computers and hospital physicians do not - part 1 : Incentives", British Medical Journal,

Berg, M. (2001), "Implementing information systems in health care organizations: myths and challenges", International Journal of Medical Informatics, Vol. 64 No. 2-3.

Becich, M.J., Gilbertson, J.R., Gupta, D., et al. (2004), "Pathology and patient safety: the critical role of pathology informatics in error reduction and quality initiatives", Clinics in Laboratory Medicine, Vol. 24 No. 4, pp. 913-943.

Braa, J., Heywood, A. and Shung King, M. (1997), "District level information systems: two cases from South Africa", Methods of Information in Medicine, Vol. 36 No. 02, pp. 115-121.

Campbell, B., Adjei, S. and Heywood, A. (1996), From Data to Decision Making in Health: The Evolution of a Health Management Information System, Royal Tropical Institute, Amsterdam.

Catassi, C.A. and Petersen, E.L. (1967), "The blood inventory control SystemHelping blood bank management through computerized inventory control”, Transfusion, Vol. 7 No. 1, p. 196.

Commission on Health Research for Development (1990), Health Research: essential Link to Equity in Development, Oxford University Press, New York, NY.

Cowan, D.F. (2005), "Laboratory informatics and the laboratory information system", in Cowan, D.F. (Ed.), Informatics for the Clinical Laboratory, Springer, New York, NY, p. 1-20.

Cummings, B.A. (1995), "RIS integration strengthens PACS. PACS under managed care", Diagn Imaging, Vol. 17, pp. 13-14.

Degoulet, P. and Fieschi, M. (1997), Introduction to Clinical Informatics, Springer, New York, NY.

DeLone, W. and McLean, E. (1992), "Information systems success: the quest for the dependent variable", Information Systems Research, Vol. 3 No. 1, pp. 60-95.

DNA (2019), "HMIS delayed: Mumbaikars won’t get rid of hospital queues soon”, available at: www. dnaindia.com/mumbai/report-hmis-delayed-mumbaikars-won-t-get-rid-of-hospital-queues-soon2710654 (accessed 7 March 2019).

Doll, W.J. and Torkzadeh, G. (1988), "The measurement of end-user computing satisfaction", MIS Quarterly, Vol. 12 No. 2, pp. 259-274.

Eleveitch, F.R. and (2001), Spackman, KA. "Clinical laboratory informatics", in Burtis, C.A. and Ashwood, E.R. (Eds), (2001), Tietz Fundamentals of Clinical Chemistry, 5th ed., WB Saunders Company, pp. 262-271.

Frere, J.J. (1987), Health and Management Information System for Child Survival Project in Pakistan, Technologies for Primary Health Care Project, United States Agency for International Development, Washington, DC, 1-23.

Frisse, M.E. and Holmes, R.L. (2007), "Estimated fi nancial savings associated with health information exchange and ambulatory care referral”, Journal of Biomedical Informatics, Vol. 40 No. 6, pp. S27-32. 
$\mathrm{XJM}$

20,1

Galliers, R.D. and Sutherland, A.R. (1991), "Information systems management and strategy formulation: the 'stages of growth' model revisited”, Information Systems Journal, Vol. 1 No. 2, pp. 89-114.

Gay, S.B., Sobel, A.H., Young, L.Q. and Dwyer, S.J. (2002), "Processes involved in reading imaging studies: workflow analysis and implications for workstation development", Journal of Digital Imaging, Vol. 15 No. 3, pp. 171-177.

Gibby, W.A. and Mciff, E.B. (1997), "Lnformactics: Radiology networking fosters quality services: Diagn lmaging”, Vol. 19, pp. 145-159.

Gladwin, J. (1999), “An informational approach to health management in low-income countries”, Ph.D. Thesis, University of Sheffield.

Hillestad, R., Bigelow, J., Bower, A., Girosi, F., Meili, R., Scoville, R., et al. (2005), "Can electronic medical record systems transform health care? Potential health benefits, savings, and costs", Health Affairs), Vol. 24 No. 5, pp. 1103-1117.

Huckvale, C., Car, J., Akiyama, M., et al. (2010), "Information technology for patient safety”, Quality and Safety in Health Care, Vol. 19 No. S2, pp. i25-33.

Husein, K., Adeyi, O., Bryant, J. and Cara, N.B. (1993), "Developing a primary health care management information system that supports the pursuit of equity, effectiveness and affordability", Social Science and Medicine (1982), Vol. 36 No. 5, pp. 585-596.

Dudeck, J., Blobel, B. and Lordieck, W. (1997), New Technologies in Hospital Information Systems, IOS Press.

Jayasuiriya, R. (1999), "Managing information systems for health services in a developing country: a case study using a contextualist framework", International Journal of Information Management, Vol. 19, pp. 335-349.

Rodrigues, J. (2009), "Health information systems: Concepts, methodologies, tools, and applications, volume 1. Medical information science reference",

Johnson, K.J., Ravert, R.D. and Avertan, A. (2001), "Hopkins teen central: assessment of an internet based support system for children with cystic fibrosis", PEDIATRICS, Vol. 107 No. 2, pp. E24.

Johnson, K.B. (2001), "Barriers that impede the adoption of pediatric information technology", Archives of Pediatrics and Adolescent Medicine, Vol. 155 No. 12, pp. 1374-1379.

Kuruvilla, S., Dzenowagis, J., Pleasant, A., Dwivedi, R., Murthy, N., Samuel, R. and Scholtz, M. (2004), "Digital bridges need concrete foundations: lessons from the health internetwork India", BMJ, Vol. 328 No. 7449, pp. 1193-1196.

Kuther, T.L. (2003), "Medical decision-making and minors: issues of consent and assent", Adolescence, Vol. 38 No. 150, pp. 343-358.

Levine, B. (1990), "A tilo of interfaces pilots communication networks", Diagn Imaging Focus on PACS 12: I.

Li, B.N., Chao, S. and Dong, M.C. (2007), "SIBAS: a blood bank information system and its 5-year implementation at Macau", Computers in Biology and Medicine, Vol. 37 No. 5, pp. 588-597.

Li, B.N., Dong, M.C. and Chao, S. (2008), "On decision making support in blood bank information systems”, Expert Systems with Applications, Vol. 34 No. 2, pp. 1522-1532.

Lifshitz, M.S., Blank Ge. and Schexneider, K. (2007), "Clinical laboratory informatics”, in McPherson, R. A. and Pincus, M.R. (Eds), Henry's Clinical Diagnosis and Management by Laboratory Methods, 21st ed., WB Saunders Elsevier. pp. 112-121.

Lippeveld, T.J., Foltz, A. and Mahouri, Y.M. (1992), "Transforming health facility-based reporting systems into management information systems: lessons from the Chad experience", Development Discussion Papers, No. 430, Harvard Institute of International Development, Cambridge, MA, pp. 1-27.

Lippeveld, T., Sauerborn, R. and Bodart, C. (2000), Design and Implementation of Health Information Systems, World Health Organization, Geneva. 
Little Johns, P. Wyatt, J.C. and Garvican, L. (2003), "Evaluating computerized health information systems: Hard lessons still to be learnt", BMJ Publishing Group Ltd. BMJ.com.

Lubitz, D.V. and Wickramasinghe, N. (2006), "Healthcare and technology: the doctrine of network centric healthcare", International Journal of Electronic Healthcare, Vol. 2 No. 4, pp. 322-344.

Lun, K.C. (1995), "The role of information technology in health care cost containment”, Singapore MedJ, Vol. 36 No. 1, pp. 32-34.

Mariani, C., Tronchi, A., Oncini, L., Pirani, O. and Murri, R. (2006), "Analysis of the x-ray work flow in two diagnostic imaging departments with and without a RIS/PACS system", Journal of Digital Imaging, Vol. 19, No. S1, pp. 18-28.

Markus, M.L. and Robey, D. (1988), "Information technology and organizational change: causal structure in theory and research", Management Science, Vol. 34 No. 5, pp. 583-598.

McKibbon, K.A., Lokker, C., Handler, S.M., et al. (2012), "The effectiveness of integrated health information technologies across the phases of medication management: a systematic review of randomized controlled trials", Journal of the American Medical Informatics Association, Vol. 19 No. 1, pp. 22-30.

McKibbon, K.A. Lokker, C. Handler, S.M. et al. (2011), "Enabling medication management through health information technology (health IT)”, Evid Rep Technol Assess (Full Rep), 1-951.

MCGM (2019), "History of municipal corporation of greater mumbai", available at: https://portal.mcgm.gov. in/irj/portal/anonymous?NavigationTarget=navurl://e73b30fff440950441693f945ad3cba7 (accessed 7 March 2019).

MCGM Health Department (2019), "Municipal corporation of greater Mumbai- Health department", available at: https:/portal.mcgm.gov.in/irj/portal/anonymous?NavigationTarget=navurl:// 0a06009b86958aea412e367434b40c52 (accessed 7 March 2019).

MCGM IT Department (2019), "Municipal corporation of greater Mumbai- Information technology department", available at: https://portal.mcgm.gov.in/irj/portal/anonymous/qlitdp?guest_user= english (accessed 7 March 2019).

MCGM RTI (2019), "Municipal corporation of greater Mumbai- Citizen forum (right to information) department manuals", available at: https:/portal.mcgm.gov.in/irj/portal/anonymous? NavigationTarget=navurl://14ebe3fd2ffb65c2dd97ceeda2158e11 (accessed 7 March 2019).

MCGM Bid Document (2018), "Bid notification no.: 7100134255: Bid document for supply, installation, testing, commissioning and maintenance of hardware and network components for MCGM's hospital management information system.' law insider", available at: https://www.lawinsider. com/documents/1Hp622wvpZJ (accessed 7 March 2019).

Miller, P.L., Frawley, S.J. and Sayward, F.G. (2001), "Issues in computer-based decision support in public health illustrated using projects involving childhood immunization", Journal of Public Health Management and Practice: Jphmp, Vol. 7 No. 6, pp. 75-86.

Mohapatra, S. (2009), Cases in Management Information System, PHI, New Delhi.

Mukul (2018), "MCGM leveraging technology to boost healthcare delivery system", available at: https:// ehealth.eletsonline.com/2019/02/mcgm-leveraging-technology-to-boost-healthcare-delivery-system/ (accessed 7 March 2019).

National Institutes of Health (2003), "Committee on data standards for patient safety. Key capabilities of an electronic health record system: Letter report", National Academies Press, Washington, DC.

Nolan, Norton and CO (1992), Ondernemingsstrategie eninformatie technologie. (NNC and VSB), The Hague.

Offenmuller, W. (1997), "Expectations and solutions for HIS/R1S/PACS dataflow and workflow", J Digit Imaging, Vol. 10, pp. 95-98.

Pearson, S., Balis, U.J., Fuller, J., et al. (2006), "Managing and validating laboratory information systems; approved guideline”, Clinical and Laboratory Standards Institute Document AUTO8-A, Vol. 26 No. 36. 
Ralston, M.D., Coleman, R.M., Beaulieu, D.M., Scrutchfield, K. and Perkins, T. (2004), "Progress toward paperless radiology in the digital environment: planning, implementation, and benefits", Journal of Digital Imaging, Vol. 17 No. 2, pp. 134-143.

Robey, D. and Boudreau, M.-C. (1999), "Accounting for the contradictory organizational consequences of information technology: theoretical directions and methodological implications", Information Systems Research, Vol. 10 No. 2, pp. 167-185.

Robey, J.M. and Lee, S.H. (1990), "Information system development in support of national health programme monitoring and evaluation: the case of the Philippines", World Health Statistical Quarterly, Vol. 43, pp. 37-46.

Rosenbloom, S.T., Qi, X., Riddle, W.R., et al. (2006), "Implementing pediatric growth charts into an electronic health record system", Journal of the American Medical Informatics Association, Vol. 13 No. 3, pp. 302-308.

Sandiford, P., Annett, H. and Cibulskis, R. (1992), "What can information systems do for primary health care? An international perspective”, Social Science and Medicine, Vol. 34 No. 10, pp. 1077-1087.

Sapirie, S.A. and Orzeszyna, S. (1995), "Selecting and defining national health indicators. Strengthening country health information unit, division of epidemiological surveillance and health situation and trend assessment", World Health Organization, Geneva, available at: www.who.int/ healthservices-delivery/information/20000629d.htm

Shearer, S.O., Miller, T. and Gillen, S. (1997), "Picture archiving and communication system implementation: the practical considerations of adapting the technology to the real world of health care operations", Journal of Digital Imaging, Vol. 10, No. S1, pp. 158-160.

Shekelle, P. Morton, S.C. and Keeler, E.B. (2006), "Costs and benefits of health information technology", Rockville (MD): Agency for Healthcare Research and Quality (US); (Evidence Reports/ Technology Assessments, No. 132).

Sinard, J.H. and Morrow, J.S. (2001), "Informatics and anatomic pathology: meeting challenges and charting the future", Human Pathology, Vol. 32 No. 2, pp. 143-148.

Sinard, J.H. (2006), "Practical pathology informatics", Demystifying Informatics for the Practicing Anatomic Pathologist, Springer. New York, NY, pp. 1-380.

Smith, D.L., Hansen, H., (1988), and., and Karim, M.S. "Management information support for district health systems based on primary health care", in Wilson RG et al. (Eds), Management Information Systems and Microcomputers in Primary Health Care, Aga Khan Foundation, Geneva, 89-110.

Smith, M.H. (1988), "National childhood vaccine injury compensation act", Pediatrics, Vol. 82 No. 2, pp. 264-269.

Tamblyn, R. (2004), "Improving patient safety through computerized drug management: the devil is in the details", HealthcarePapers, Vol. 5 No. 3, pp. 52-68.

The Hindu (2018), "Dynacons systems bags contract worth ₹58 cr", available at: www. thehindubusinessline.com/markets/stock-markets/dynacons-systems-solutions/article24856706. ece (accessed 7 March 2019).

Twelfth Five year Plan Draft 2012 (2017), "Social sectors, vol. 3.Govt. of India", available at: http:// planningcommissiongov.in/plans/planrel/12thplan/welcome.html

Van Der Lei, J., Duisterhout, J.S., Westerhof, H., Boon, W., Cromme, P.V.M. and Van Bammel, J.H. (1993), "The introduction of computer based patient records in The Netherlands", Annals of Internal Medicine, Vol. 119 No. 10, pp. 1036-1041.

Van Hartevelt, J.H.W. (1993), "Information management in international development as an area for information services with a case in the field of health care in Ghana", International Forum on Information and Documentation, Vol. 18, pp. 32-36.

Veader, P.C. (1997), “The missing links”, February 16, 1997; Online: Peter C. Veader: Internet: August, Vol. 30, 1997 
Wang, S.J., Middleton, B., Prosser, L.A., Bardon, C.G., Spurr, C.D., Carchidi, P.J., et al. (2003), “A costbenefit analysis of electronic medical records in primary care", The American Journal of Medicine, Vol. 114 No. 5, pp. 397-402.

White, K.S. (2005), "Speech recognition implementation in radiology”, Pediatric Radiology, Vol. 35 No. 9, pp. 841-846.

World Bank (1993), World Development Report 1993: Investing in Health, Oxford University Press, New York, NY.

World Bank (1999), World Development Indicators 1999, The World Bank, Washington, DC.

Yasnoff, W.A., O'Carroll Patrick, W., Koo, D., Linkins Robert, W. and Kilbourne, E.M. (2000), "Public health informatics: Improving and transforming public health in the information age", Journal of Public Health Management and Practice: Jphmp, Vol. 6 No. 6, pp. 67-75.

Young, K.M. (2000), The World of Informatics: informatics for Healthcare Professionals, F.A. Davis Company, Philadelphia, p. 11-24.

\section{Further reading}

Chaudhry, B., Wang, J., Wu, S., Maglione, M., Mojica, W., Roth, E., Morton, S.C. and Shekelle, P.G. (2006), "Systematic review: Impact of health information technology on quality, efficiency and costs of medical care, improving patient care", Annals of Internal Medicine, Vol. 144 No. 10, pp. 742-752.

Connelly, D.P., Sielaff, B.H. and Willard, K.E. (1996), "The clinical workstation as the means of improving laboratory use", Clinica Chimica Acta, Vol. 248 No. 1, pp. 51-64.

Kallinikos, J. (2005), "The order of technology: Complexity and control in a connected world", Information and Organization, Vol. 15 No. 3, pp. 185-202.

Kallinikos, J, Contini and Lanzara (2008), "Institutional complexity and functional simplification: the case of money claim online service in England and Wales", in (Eds) ICT and Innovation in the Public Sector. European Studies in the Making of E-Governmen, Palgrave Macmillan, Basingstoke, pp. 174-210.

Lanzara, G.F. (2008), "Building digital institutions: ICT and the rise of assemblages in government", in Contini and Lanzara (Eds), ICT and Innovation in the Public Sector. European Studies in the Making of E-Government, Palgrave Macmillan, Basingstoke, pp. 9-48.

Margolis, C.Z., Warshawsky, S.S., Goldman, L., Dagan, O., Wirtschafter, T. and Pliskin, J.S. (1992), "Computerized algorithms and pediatricians management of common problems in a community clinic", Acad Med, Vol. 67, pp. 282-284.

Schoenbaum, S.C. and Barnett, G.O. (1992), "Automated ambulatory medical records systems: an orphan technology", International Journal of Technology Assessment in Health Care, Vol. 8 No. 4 , pp. 598-609.

Schriger, D.L., Baraff, L.J., Buller, K., et al. (2000), "Implementation of clinical guidelines via a computer charting system: effect on the care of febrile children less than three years of age", Journal of the American Medical Informatics Association, Vol. 7 No. 2, pp. 186-195.

Scott, J.C. (1988), Seeing like a State: How Certain Schemes to Improve the Human Condition Have Failed, Yale University Press. 
$\mathrm{XJM}$

20,1

78

Figure A1.

Mumbai city map

\section{Appendix}

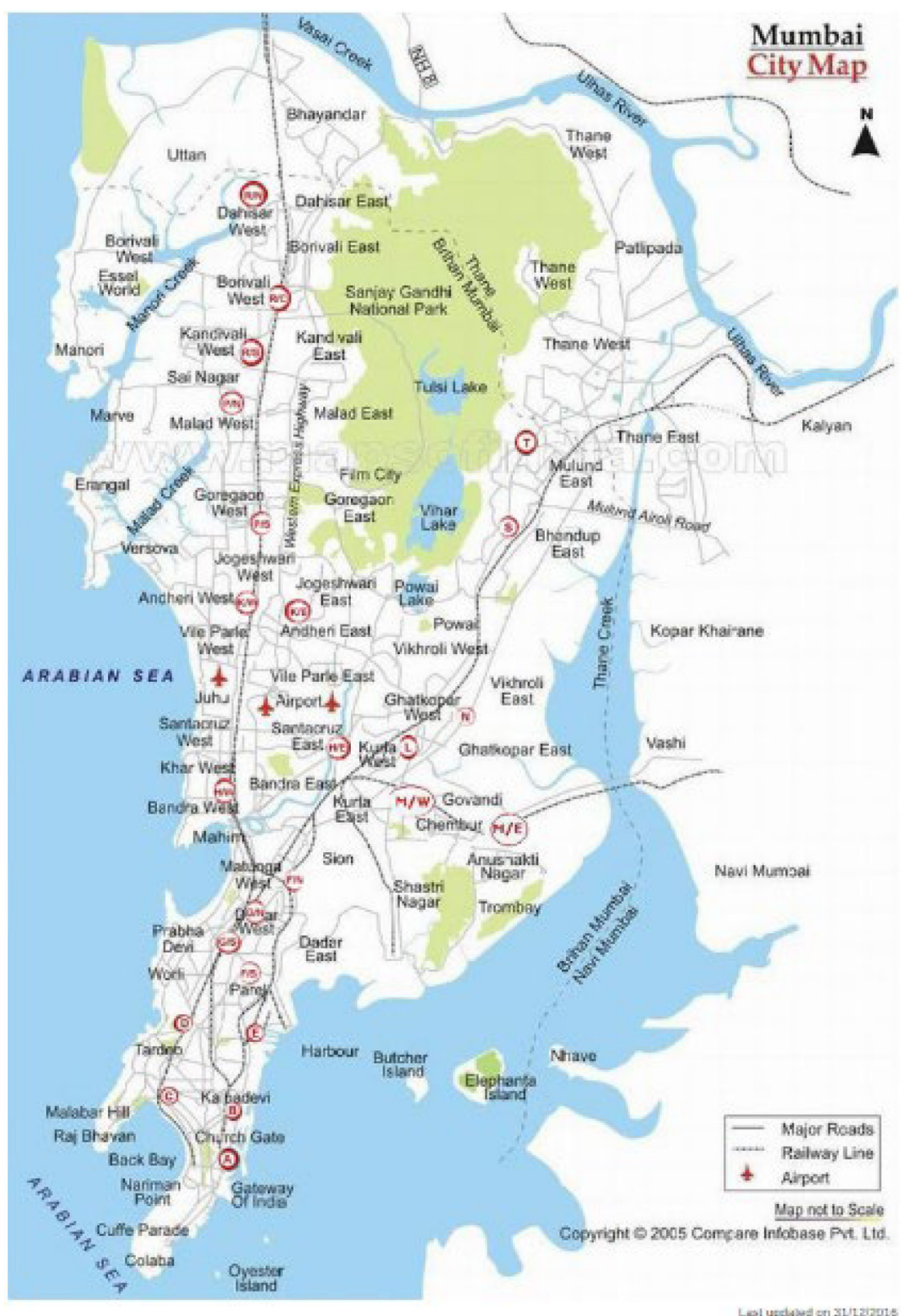

Source: available at: https://portal.mcgm.gov.in 


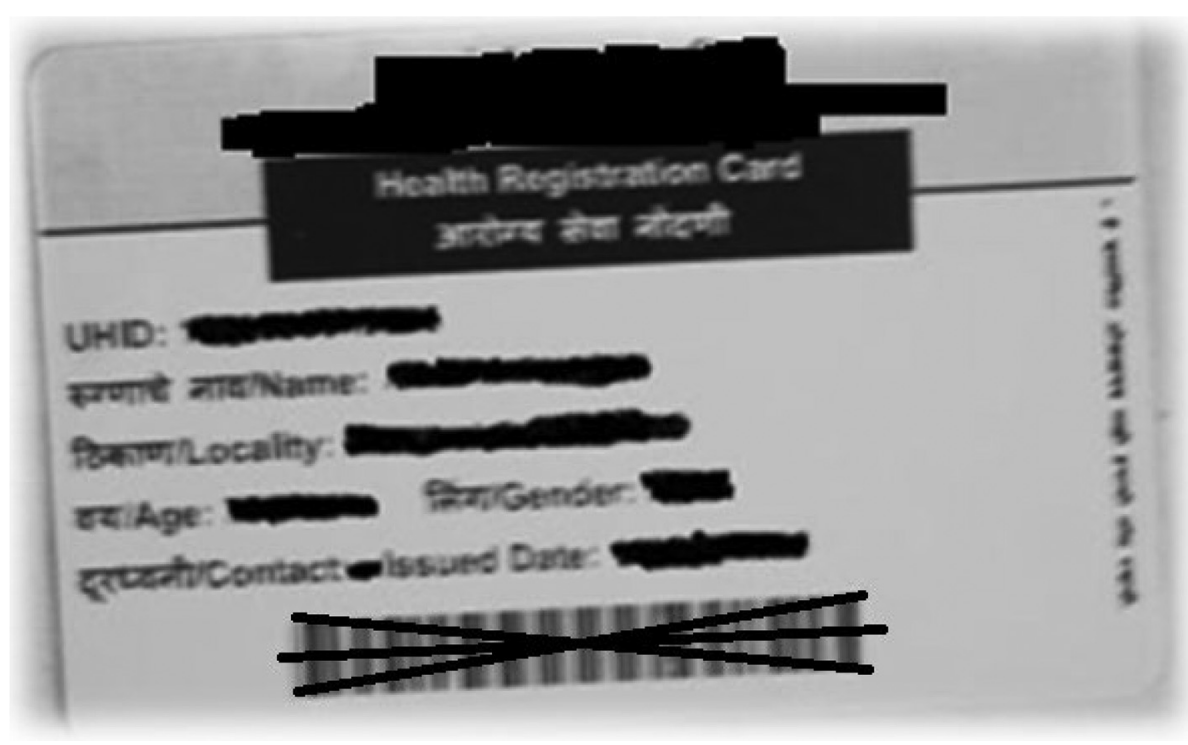

\section{Hospital management information system}

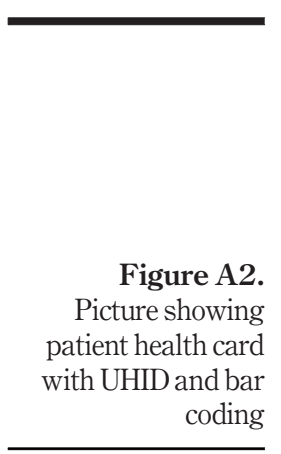

Section of hospital

Number of trolleys distributed

Ward 7

Neuro OT

TB OPD

Medical OPD

ICCU 1

Pharmacy department

Medical store

AMO office

Dispensary

Ward 1

Pulmonary medicine

Ward 2

Ward 3

MSW

OPD 1

Laundry

Ward 4

Ward 5

Endocrinology department

OPD 2

Ward 6

Ward 7

ICCU 2

Miscellaneous

Total

2

1

20

5

4

5

1

5

4

4

4

4

7

28

1
10

8

3

15

5

3

10

47

200
Table A1.

Table showing distribution of customized computer trolleys at Film City's Hospital 


\begin{tabular}{|c|c|c|c|}
\hline KPI & $\begin{array}{c}\text { December } 2018 \\
(\%)\end{array}$ & $\begin{array}{c}\text { January } 2019 \\
(\%)\end{array}$ & $\begin{array}{c}\text { February } 2019 \\
(\%)\end{array}$ \\
\hline $\begin{array}{l}\text { Percentage EMR completed } \\
\text { Human resources KPIs }\end{array}$ & 17.65 & 36.02 & 39.31 \\
\hline Average overtime hours worked per employee & 10.31 & 6.40 & 6.35 \\
\hline $\begin{array}{l}\text { Percentage of training programs in which Informatics was } \\
\text { included }\end{array}$ & 35.00 & 47.00 & 52.00 \\
\hline Employee turnover & 10.05 & 11.25 & 13.12 \\
\hline $\begin{array}{l}\text { Employee satisfaction } \\
\text { Quality KPIs }\end{array}$ & 74.67 & 69.25 & 62.33 \\
\hline Percentage of incidents reported & 5.2 & 4.5 & 3.9 \\
\hline $\begin{array}{l}\text { Readmission rate } \\
\text { Patient KPIs }\end{array}$ & 9.5 & 10.5 & 9.5 \\
\hline Patient satisfaction & 77.67 & 80.05 & 82.25 \\
\hline $\begin{array}{l}\text { Percentage of monthly complaints } \\
\text { Radiology KPIs }\end{array}$ & 17.8 & 17.4 & 15.2 \\
\hline Percentage change in imaging turnaround time & 46.25 & 40.45 & 39.25 \\
\hline $\begin{array}{l}\text { Percentage of reports generated per full time radiologist } \\
\text { Laboratory KPIs }\end{array}$ & 52.52 & 55.33 & 61.65 \\
\hline Percentage change in report turnaround time & 44.35 & 38.32 & 34.25 \\
\hline $\begin{array}{l}\text { Percent change in operational cost } \\
\text { Pharmacy KPIs }\end{array}$ & 43.66 & 41.25 & 42.33 \\
\hline $\begin{array}{l}\text { Percentage of dispensing errors reported } \\
\text { Informatics KPIS }\end{array}$ & 4.5 & 4.3 & 3.8 \\
\hline Downtime & 24.50 & 14.25 & 19.55 \\
\hline Percentage of instances of lost data/images & 21.66 & 20.05 & 17.25 \\
\hline
\end{tabular}

Table A2.

Changes in key performance indicators (KPIs) at Film City's Hospital after HMIS implementation

\begin{tabular}{lcc}
\hline Services & Before HMIS & After HMIS \\
\hline Registration process & $00: 04: 16$ & $00: 02: 47$ \\
Consultation process & $00: 03: 21$ & $00: 03: 16$ \\
Discharge process & $00: 05: 53$ & $00: 04: 48$ \\
Drug dispensing & $00: 04: 22$ & $00: 03: 18$ \\
Blood test & $00: 04: 33$ & $00: 03: 47$ \\
Ultrasonography & $00: 04: 54$ & $00: 04: 38$ \\
MRI & $00: 05: 57$ & $00: 05: 01$ \\
\hline
\end{tabular}

Table A4.

Average gain per unit volume of the services

\begin{tabular}{lcc}
\hline Services & Before HMIS & After HMIS \\
\hline Pharmacy services & Rs. 11 & Rs. 14 \\
Consultation services & Rs. 10 & Rs. 11 \\
Laboratory services & Rs. 8 & Rs. 12 \\
Radiology services & Rs. 11 & Rs. 12 \\
Endoscopy services & Rs. 8 & Rs. 9 \\
\hline
\end{tabular}


Hospital

management

information

system

Mean response on five-point scale

Element (Strongly disagree to Strongly agree)

Confidence is using HMIS

Simplicity of use

Inconsistency of system

Well integrated system

Complex system

Feel need for learning/training

Requirement for technical assistance

3.98

Table A5.

Employees $(n=75)$

responses for HMIS

\section{Corresponding author}

Lakshya Arora can be contacted at: lakshya1011@gmail.com

For instructions on how to order reprints of this article, please visit our website: www.emeraldgrouppublishing.com/licensing/reprints.htm

Or contact us for further details: permissions@emeraldinsight.com 